BMJ Open Sport \& Exercise Medicine

\title{
Postmatch recovery of physical performance and biochemical markers in team ball sports: a systematic review
}

\author{
Steven H Doeven, ${ }^{1,2}$ Michel S Brink, ${ }^{1}$ Silke J Kosse, ${ }^{1}$ Koen A P M Lemmink ${ }^{1}$
}

To cite: Doeven SH, Brink MS, Kosse SJ, et al. Postmatch recovery of physical performance and biochemical markers in team ball sports: a systematic review. BMJ Open Sport \& Exercise Medicine 2018;4:e000264. doi:10.1136/ bmjsem-2017-000264

- Additional material is published online only. To view please visit the journal online (http://dx.doi.org/10.1136/ bmjsem-2017-000264)

Accepted 27 November 2017
Check for updates

${ }^{1}$ Center for Human Movement Sciences, University of Groningen, University Medical Center Groningen, The Netherlands

${ }^{2}$ School of Sport Studies, Hanze University of Applied Sciences, Groningen, The Netherlands

Correspondence to MSc Steven H Doeven; s.h. doeven@pl.hanze.nl

\section{ABSTRACT}

Background Insufficient postmatch recovery in elite players may cause an increased risk of injuries, illnesses and non-functional over-reaching.

Objective To evaluate postmatch recovery time courses of physical performance and biochemical markers in team ball sport players.

Study design Systematic review.

Data sources PubMed and Web of Science. Eligibility criteria for selecting studies This systematic review was conducted according to Preferred Reporting Items for Systematic Reviews and Meta-Analyses guidelines. The Critical Review Form for Quantitative Studies was used to evaluate quality. Studies were included if they met the following criteria: (1) original research evaluated players' physical recovery postmatch; (2) team/intermittent sports; and (3) at least two postmeasurements were compared with baseline values. Results Twenty-eight studies were eligible. Mean methodological quality was $11.2 \pm 1.11$. Most used performance tests and biochemical markers were the countermovement jump test, sprint tests and creatine kinase (CK), cortisol (C) and testosterone $(\mathrm{T})$, respectively. Summary/conclusions The current evidence demonstrates that underlying mechanisms of muscle recovery are still in progress while performance recovery is already reached. CK recovery time courses are up to $\geq 72$ hours. Soccer and rugby players need more time to recover for sprint performance, $\mathrm{CK}$ and $\mathrm{C}$ in comparison to other team ball sports. There are more high-quality studies needed regarding recovery in various team sports and recovery strategies on an individual level should be evaluated

Clinical relevance Ongoing insufficient recovery can be prevented by the use of the presented recovery time courses as specific practical recovery guidelines.

\section{INTRODUCTION}

Elite team sports players are exposed to busy schedules of training and matches. During the competitive season, players have a match every week and sometimes even twice a week due to international competitions and domestic Cup league matches. In elite soccer, players participate in approximately 60 matches during a season, which equates 5.5 matches per month. ${ }^{1}$ These highly congested match schedules put a lot of strain on these
What is already known on this subject?

- The recovery process is challenging to manage in team ball sports and depends on several contextual factors.

- Multiple performance tests and biochemical markers are used to monitor the time course of recovery after training and matches.

- Physical performance recovery takes up to $\geq 48$ hours after regular training.

\section{What are the new findings?}

- After matches, underlying mechanisms of muscle recovery last up to $\geq 72$ hours, despite recovery of physical performance after $\geq 48$ hours.

- For soccer and rugby the time course of recovery is longer in comparison to other team ball sports for performance tests (sprint) and biochemical markers (creatine kinase and cortisol).

- Clinical vigilance on 'hidden' recovery may prevent ongoing insufficient recovery in elite team sport players.

players. In addition, studies reveal the high intensity and variable character of intermittent team ball sports of which the time course of match recovery is unknown. ${ }^{2-4}$ To be able to prevent health problems and to perform at the highest possible level, sufficient recovery is crucial in this matter. ${ }^{5}$

In order to plan subsequent training sessions or prepare for upcoming matches, knowledge is needed about time courses of recovery. ${ }^{6-8}$ Although match performance is highly variable and depends on several contextual factors, it is assumed that the intensity during matches is maximal and most strain is placed on players. Profiles of physical performance and biochemical markers after a match in team ball sports (eg, soccer, rugby, handball, basketball, Australian rules football) are needed in order to get a realistic view of recovery and underlying mechanisms. ${ }^{6910}$ These different types of sport have likely unique recovery 
profiles caused by the diversity of game demands such as number of jumps, sprints and collisions. ${ }^{411}{ }^{12}$ By comparing profiles within and between different team ball sports, all of which are characterised by high-intensity and intermittent activities, the recovery process will be better understood.

Different tests and measurements can be used for monitoring recovery and performance. ${ }^{9}$ There are multiple physical performance tests (eg, jump, sprint, strength, agility, flexibility, technical and aerobic tests) which could be used. Furthermore, biochemical markers (eg, creatine kinase (CK), cortisol (C) and testosterone (T)) in blood and saliva samples could identify the underlying physiology of the recovery process ${ }^{9}$ after playing a match and contribute in the determination of the time course of match recovery. Finally, self-reported measures (eg, Profile of Mood States or Recovery Stress Questionnaire for Athletes) are demonstrated to be highly relevant to monitor the training response. ${ }^{13}$

In order to get a better understanding of postmatch recovery kinetics this systematic review focuses on performance tests and biochemical markers in team ball sports. Indeed self-reported measures showed to be sensitive and evaluate multiple constructs in one single measure for monitoring. Although this can be seen as an advantage in daily practice it also limits understanding of which factors play an important role in recovery kinetics after matches. Therefore, we systematically reviewed recovery profiles postmatch of objectively measured indicators in team ball sports.

Knowledge of physical performance tests and biochemical markers that reflect the magnitude of change in volume and or intensity of the preceding match ${ }^{14}$ is needed for creating balanced training schedules. Appropriate time between the match and the next training impulse should be applied to prevent injuries, illnesses and non-functional over-reaching and achieve optimal performance.

Johnston $e t a l^{15}$ recently investigated performance and biochemical responses after training. Although immediately post-training a decrease in performance together with an increase in CK was reported, performance was at pretraining level after 2 hours while CK continues to increase. This suggests that performance again may be normal, but that underlying systems are still recovering. To date, there is no review available that compares objective recovery measures after matches. Therefore, the aim of this review is to synthesise recovery time courses for matches. Based on the variation in match load in different team ball sports typical recovery patterns are expected and therefore require planning. Furthermore, the course of recovery of performance might deviate from biochemical markers. So, in sum, the main aim of this systematic review is to evaluate postmatch recovery time courses of physical performance tests and biochemical markers in team ball sports.

\section{METHODS}

This systematic review was reported according to the Preferred Reporting Items for Systematic Reviews and Meta-Analyses statement. ${ }^{16}$

\section{Literature search}

A systematic literature search was performed in the databases of PubMed and Web of Science for relevant articles. The search included all available articles which were written in English or Dutch from the period between January 1985 and October 2016. Both databases were searched with the following terms (1 AND 2 AND 3):

1. Match (OR Game OR Competition OR PostMatch)

2. Recovery (OR Countermovement Jump OR Counter Movement Jump OR Repeated Sprint Ability OR Creatine Kinase OR Cortisol OR Testosterone)

3. Team (OR Intermittent OR Player OR Sport OR Baseball OR Basketball OR Football OR Hockey OR Soccer OR Volleyball OR Rugby OR Handball)

Term 1 was restricted to the title to prevent the inclusion of clinical papers. Also, the cursive terms were used as MeSH terms in PubMed (eg, Medical Subject Headings). In PubMed, a preselection was set on text availability (full text), species (human) and language (English and Dutch). All studies found in both databases were taken together after which duplicates were removed.

\section{Literature selection}

The first selection of the articles for potential relevance was determined based on title and afterwards on abstract. Of the residuals full texts were obtained and read. Two authors (SHD and SJK) analysed the articles independently. The included articles' reference lists were searched for relevant articles which were not found by using the initial search strategy. Original research articles were included if they investigated physical recovery of players (mean age $\geq 18$ years) after a match in intermittent sports. An important condition was that at least two postmeasurements were compared with a baseline measurement. Intermittent sport was defined as a sport in which players stop and start often and for short periods. As a result, all team sports were included. Studies were excluded if: (1) full text was not available; (2) the article was not published in English or Dutch; (3) data were not reported in numbers in tables and/or text; (4) recovery strategies were used; (5) the study was an intervention; (6) participants were injured, ill, disabled, overtrained or recovering from injury, illness, disability or overtraining; (7) only one postmeasurement was reported; and (8) there was no baseline measurement. If the two authors disagreed on inclusion, a third author (MSB) decided whether the article was included or not.

\section{Data extraction}

Data were extracted from all included articles when statistical significance or a meaningful effect size (ES) 


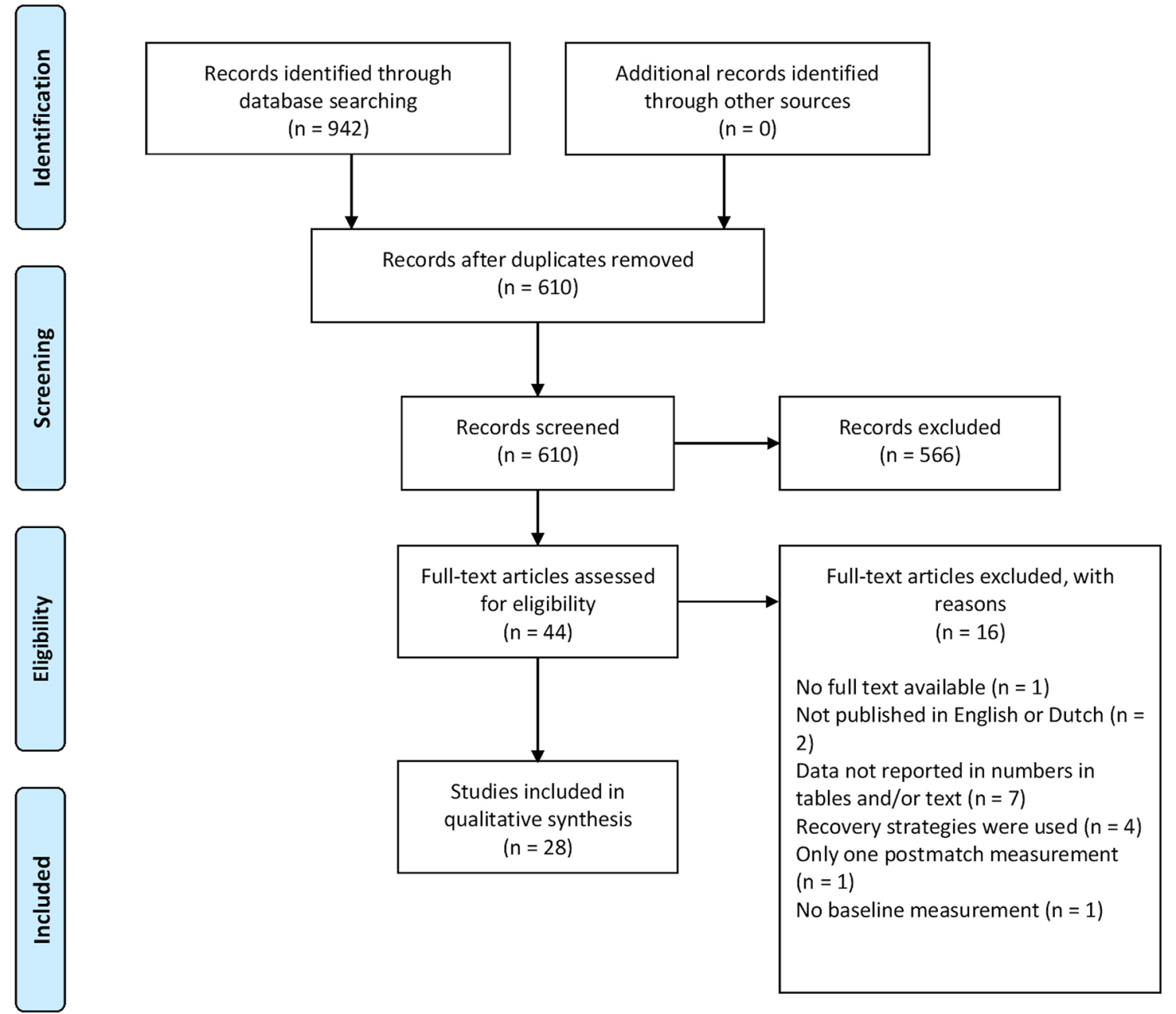

Figure 1 Eligibility flow diagram.

across repeated measurements was presented in a result table and/or text. ES (Hedges' $g$ ) were calculated when not reported by the authors and mean, SD and number of participants were reported in absolute numbers. ES ranges were presented for performance tests and biochemical markers using the following criteria: $<0.2=$ trivial, $0.2-0.6=$ small, $0.6-1.2=$ moderate, 1.2-2.0=large and $>2.0=$ very large ${ }^{17}$ The characteristics of the subjects were extracted from the articles, as well as the sport and type, intensity and duration of the exertion. Furthermore, times of measurements and tests which were used to measure recovery were extracted. All values were converted to percentages, so the reported values of different studies could be compared. Also, protocols were checked and compared with to see whether there were large differences between the protocols of the different studies.

\section{Methodological quality}

Two authors (SHD and SJK) assessed the methodological quality of the included articles based on The Critical Review Form for Quantitative Studies. ${ }^{18}$ These guidelines consisted of 14 criteria: (1) Was the study purpose stated clearly? (2) Was relevant background literature reviewed? (3) Was the design appropriate for the research question? (4) Was the sample described in detail? (5) Was the sample size justified? (6) Was informed consent obtained? (7) Were the outcome measures reliable? (8) Were the outcome measures valid? (9) Were results reported in terms of statistical significance? (10) Were the analysis methods appropriate? (11) Was clinical importance reported? (12) Were conclusions appropriate given the study methods? (13) Are there any implications for clinical practice given the results of the study? (14) Were limitations of the study acknowledged and described by the authors? In line with the scope of this systematic review criteria, 13 was also positively assessed when a 'practical applications' section was included in the article.

The different criteria were scored with ' 1 ' if it was met and it was scored with ' 0 ' if it was not met. This resulted in quality scores ranging from 0 to 14 . Articles with a score below 7 were considered to have a poor methodological quality. Articles with scores between 7 and 10 were considered to have a good methodological quality. If an article scored over 10 it was considered to have a high methodological quality. ${ }^{18}$ 


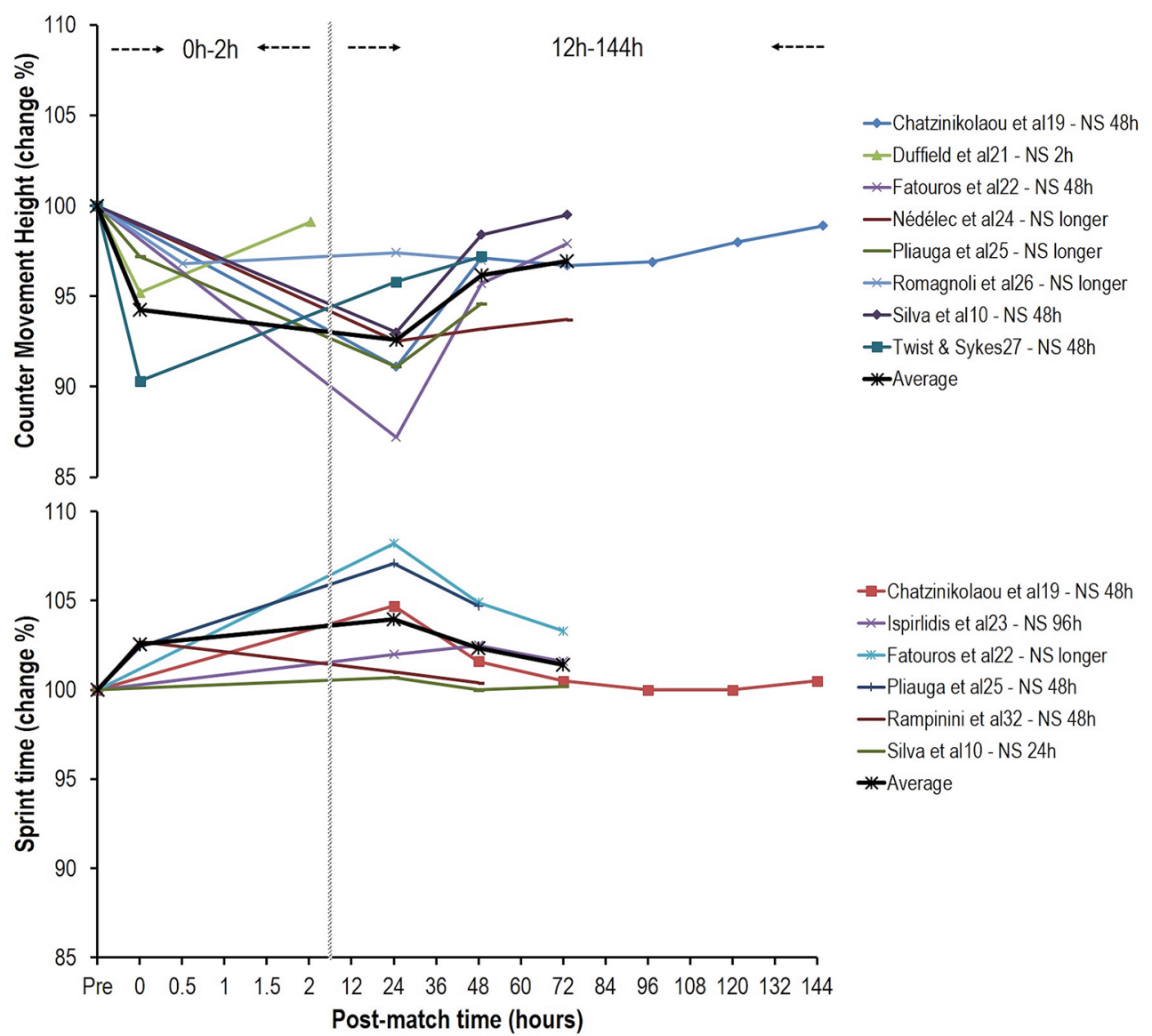

Figure 2 Recovery time course changes (\%) in countermovement jump height and sprint time from prematch to 144 hours postmatch. All studies were set on $100 \%$ prematch. NS, non-significant from baseline values.

\section{RESULTS}

Figure 1 shows the eligibility flow diagram. The initial search yielded a result of 321 studies in PubMed and 621 studies in Web of Science. After removing duplicates and application of the inclusion and exclusion criteria, 28 articles were included in this study. The online supplementary table shows the characteristics and main findings of the included studies. In total, 59 physical performance tests and biochemical markers were used to measure recovery. The mean score for the methodological quality of the studies included was $11.2 \pm 1.11$, which indicates good to high methodological quality. Twenty-six out of 28 studies scored at least 10 points or higher. None of the studies scored below 7 .

\section{Physical performance tests}

Twelve studies used the countermovement jump (CMJ) as performance test to assess changes in jump height. ${ }^{1019-29}$ Reduced jump height indicated that the player was not yet fully recovered. However, there were also studies which used CMJ for different outcomes, such as peak power, ${ }^{6} 3031$ peak force, ${ }^{30}{ }^{31}$ mean power, mean force, flight time, contraction time or flight time:contraction time..$^{20}$ The reported results for CMJ height can be found in figure 2 (ES range 0.24-1.22). The decrease in $\mathrm{CMJ}$ height ranged from 1.6 to $6 \mathrm{~cm}$. Two studies show that CMJ height was decreased most immediately ${ }^{21} 27$ or 30 min postmatch. ${ }^{26}$ Other studies did not measure immediately postmatch except for one study. ${ }^{25}$ These studies showed strongest decrease for CMJ height at $12^{29}$ or $24^{101922-25}$ hours postmatch. In one study, CMJ height was returned to baseline after 2 hours. ${ }^{21}$ In the other studies CMJ height returned to baseline after $48^{10222327}$ and $60^{29}$ hours. There were three studies in which CMJ height did not increase to baseline values within the last measurement at $48^{2526}$ or $72^{24}$ hours postmatch of that study.

Six studies used sprint time to asses recovery, measured over the following distances: $5,{ }^{10} 10,{ }^{19}{ }^{25} 20,{ }^{22} 2330^{10}$ and $40^{32} \mathrm{~m}$. Figure 2 shows the reported results for sprint time over different distances, the results of $5 \mathrm{~m}$ sprints are not displayed (ES range 0.30-1.10). All studies, except for one,${ }^{23}$ showed the strongest increase in sprint time at the first measurement after the match. This was immediately postmatch ${ }^{2532}$ or at $24^{101922}$ hours postmatch. Sprint time was returned to baseline values after, respectively, $48^{101932}$ or $96^{23}$ hours. There were two studies in which sprint time did not decrease to baseline values within the last measurement at $48^{25}$ or $72^{22}$ hours postmatch of that study. In one study, none of the values were significantly different from premeasurement. ${ }^{10}$

Other performance tests which were used are, for example, the maximum voluntary contraction test, ${ }^{21} 2432$ 


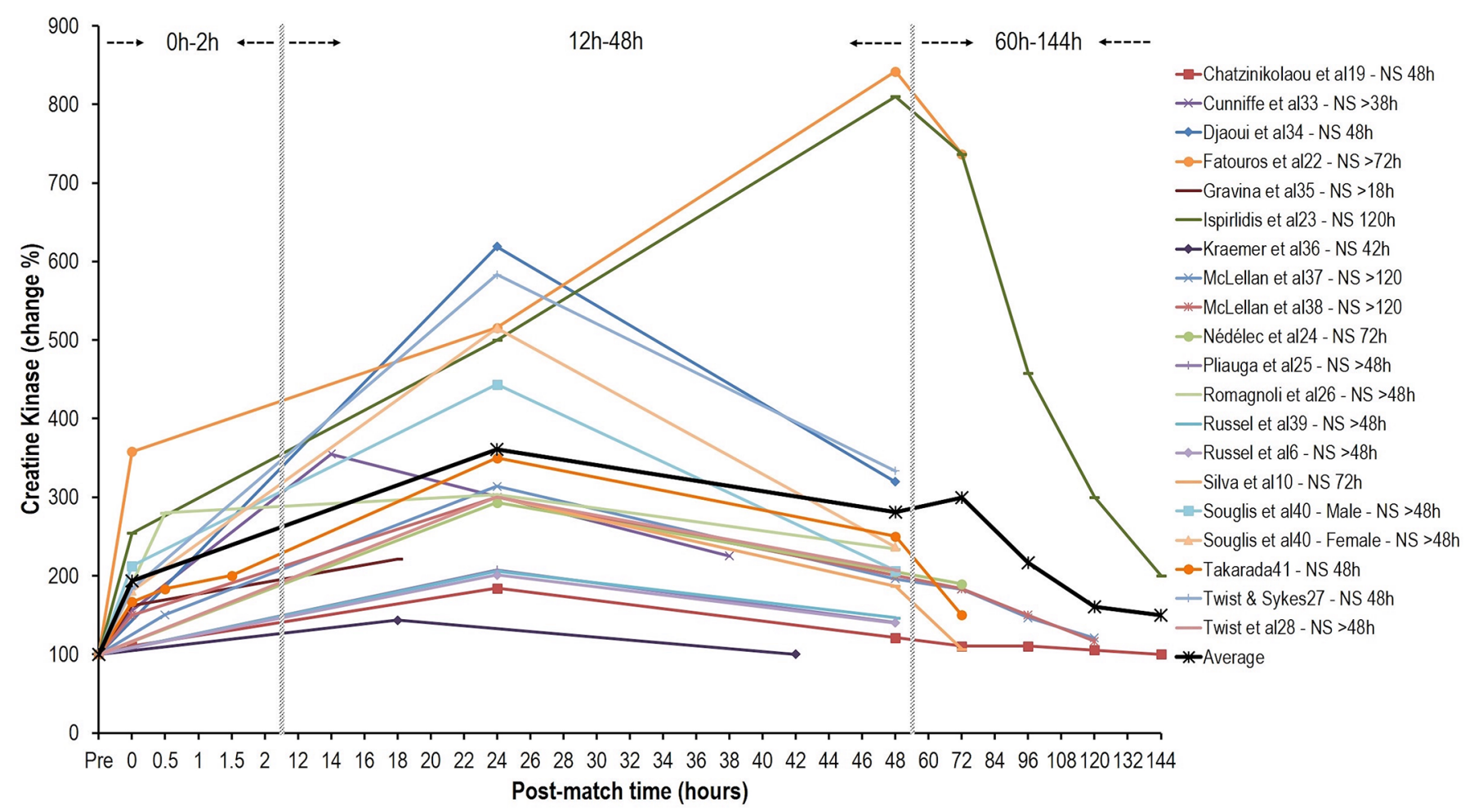

Figure 3 Recovery time course changes (\%) in creatine kinase from prematch to 144 hours postmatch. All studies were set on $100 \%$ prematch. NS, non-significant from baseline values.

muscle function tests, ${ }^{1927}$ squat jump ${ }^{30}$ and line drill test ${ }^{19}$ (online supplementary table).

\section{Biochemical markers}

CK was the most frequently used biochemical marker and assessed in 19 studies. $^{6} 1019$ 22-28 33-41 The extent of increase in CK concentration differed among the studies (ES range 0.54-7.80) (figure 3). In seven studies, peak values ranging from 100 to $500 \mathrm{U} / \mathrm{L}$ were reported. ${ }^{19}$ 25-28 3536 Twelve studies reported peak values which were strongly increased in comparison to their premeasurement; values that were six or seven times higher were presented. These values ranged from 671 to $1411 \mathrm{U} /$ L. $^{6} 10$ 22-24 $333437-41$ Fourteen studies found peak values 24 hours postmatch. ${ }^{6} 101924-283437-41$ In the other studies peak values were reported after $14,{ }^{33}$ $18^{35} 36$ or $48^{22} 23$ hours. In 12 studies, CK concentration did not decrease to baseline within the times of

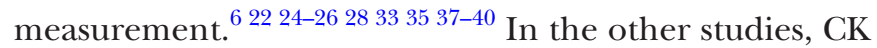
concentration returned to baseline after $42,{ }^{36} 48,{ }^{19} 273441$ $72^{10}$ or 120 hours. ${ }^{23}$

Other biochemical markers which were often used were $\mathrm{C}$ and $\mathrm{T}$ (online supplementary table). Eleven studies used $\mathrm{C}^{10} 19202326293336-3842$ and $\mathrm{T}^{10} 19202326293335363842$ $\mathrm{T}: \mathrm{C}$ ratio as anabolic/catabolic balance was calculated in eight studies. ${ }^{10} 20262933363842$

There were six studies which measured the concentration of C from blood samples ${ }^{10} 1923263336$ and five studies measured it from saliva samples. ${ }^{20} 29373842$ Peak values measured from blood samples ranged from 219 to $662 \mathrm{nmol} / \mathrm{L}$, whereas peak values measured from saliva samples ranged from 16.3 to $80 \mathrm{nmol} / \mathrm{L}$. All studies reported peak values immediately after the match, except for one study ${ }^{20}$ and the ones that did not measure immediately after. ${ }^{10} 2936$ These studies reported peak values at $14,{ }^{29} 18-20,{ }^{36} 24^{20}$ and $48^{10}$ hours postmatch. In two studies, $\mathrm{C}$ was decreased to baseline values after 24 hours. ${ }^{19}{ }^{23}$ In the other studies this was at $14,{ }^{33} 48,{ }^{37} 38$ $60^{29}$ or $72^{10}$ hours. In three studies values became significantly different again at $38^{33}$ and $96^{3738}$ hours postmatch. In one study $\mathrm{C}$ was decreased for 48 hours postmatch. ${ }^{26}$ However, there were also two studies in which none of the values were reported as significantly different from baseline.$^{2036}$ One study did not compare values with baseline measurements. ${ }^{42}$

Seven studies measured the concentration of $\mathrm{T}$ from blood samples, ${ }^{10} 192326333536$ the other four studies used saliva samples. ${ }^{20} 293842$ In four studies T concentration did not clearly increase or decrease prematch or postmatch. ${ }^{10} 192336$ One study reported a strong decrease prematch ${ }^{38}$ followed by an increase postmatch with two other studies. ${ }^{35} 3842$ In four studies $\mathrm{T}$ concentration decreased postmatch. ${ }^{2026} 2933$ T concentration increased again to baseline values within $24^{29} 33$ or $48^{20}$ hours or stayed significantly different after $48^{26}$ hours.

Finally, the online supplementary table shows that six and five studies measured leucocytes ${ }^{71922} 233335$ and uric acid, ${ }^{1019222335}$ respectively. C-reactive protein ${ }^{10} 192326333540$ and interleukin-6 61923263340 were respectively used in seven and six studies. Other biochemical markers that were used are, for example, myoglobin,,$^{10}{ }^{41}$ lactate 
dehydrogenase, ${ }^{233536}$ protein carbonyls ${ }^{1922} 23$ and salivary immunoglobulin A. ${ }^{43}$

\section{DISCUSSION}

The main purpose of this systematic review was to synthesise postmatch recovery time courses of physical performance tests and relevant biochemical markers in team ball sports. The main finding is that physical test performance (eg, CMJ height and sprint time) returned to baseline after 48 hours in most studies. ${ }^{10} 1922232732$ For the biochemical tests, higher variability within and between studies and tests is shown. In 14 out of 19 studies, CK returned to baseline after $\geq 72$ hours ${ }^{1022-243738}$ or did not decrease to baseline within the times of measurement. 622 24-26 $28333537-40$

\section{Performance tests: role of type of sport, exertion and playing level}

CMJ height was the most used performance test among the included studies. Players needed at least 48 hours to return to prematch values on this test, with the exception of one study. ${ }^{21}$ Sprint time was also used often as an indicator of recovery. Recovery time of sprint ranged from 24 to 96 hours. CMJ height and sprint time were measured only in male players in the included studies and ES were small to moderate. In the literature, the validity, reliability and sensitivity of performance test were subject to debate. ${ }^{44}$ For example, the value of jump height for measuring recovery is limited. Rowell et $a l^{14}$ recently showed that flight time:contraction time is a more sensitive measure of recovery. Although small within-player variation (coefficient of variation $(\mathrm{CV})<5 \%$ ) and high intraclass correlation coefficient (ICC) are reported for the CMJ and sprint tests, ${ }^{45-52}$ the included studies showed CVs up to $12.8 \%$ and $8.2 \%$, respectively. Changes exceed normal variation and thus are relevant.

For CMJ height, one explanation for the length of recovery time courses can be type of sport. Our results indicate relatively longer recovery time courses for basketball in comparison to other team ball sports. One basketball study needed more than 48 hours to reach non-significant values. ${ }^{25}$ This can be confirmed by another basketball study that reported 96 hours. ${ }^{53}$ The longer recovery time courses can be explained by the high number of jumps performed during basketball matches. $^{12255455}$

For sprint time, duration of recovery time courses can be explained by type of sport, duration of exercise and type of exertion. Two out of four soccer studies reported that more than 72 hours was needed to recover to baseline values. ${ }^{22} 23$ The other types of sports, basketball ${ }^{25}$ and handball, ${ }^{19}$ showed shorter recovery time courses (eg, between 48 and 72 hours). Variability in the duration of total playing time between soccer $(2 \times 45 \mathrm{~min})$, basketball $(4 \times 12 \mathrm{~min})$ and handball $(2 \times 30 \mathrm{~min})$ is evident. It might be expected that longer duration of exercise causes longer sprint recovery time courses. Furthermore, in contrast with soccer, basketball and handball are influenced by interruptions (eg, timeouts, time between quarters, match stops) and the use of substitutions. More short-term recovery in sprint time can be expected when performing these intermittent sports compared with soccer.

Finally, for both CMJ height and sprint time, physical fitness indicated by differences in competition level might explain variability between study results. ${ }^{56}$ One study with non-elite players showed a strong decrease in CMJ height directly postmatch. ${ }^{27}$ This is in accordance with Magalhães et al's ${ }^{57}$ study that showed a strong decrease followed by a long recovery period ( $>72$ hours) in second and third division soccer players. The sharp drop in jump height and subsequent longer recovery time may indicate that lack of physical fitness in these amateur players affects recovery. A similar pattern is seen in sprint time. This was relatively high at the lower level in comparison to the elite level. ${ }^{575}$ Players played second and third divisions $^{57}$ and secondary division, ${ }^{58}$ respectively. In these studies, sprint time also needed to recover longer.

\section{Biochemical markers and variability of recovery kinetics}

The most used biochemical markers to monitor recovery were CK, C and T. Except for one study, ${ }^{35}$ strict protocols were set up for measuring these biochemical markers. Players followed a controlled diet, were measured at exactly the same times of the day and were excluded from heavy exercise other than the match during the measurements. Although CK (ES were large to very large) shows high variability $(\mathrm{CV}>25 \%)$ between individual players and poor sensitivity, ${ }^{52}$ 59-62 the included studies showed CVs up to $>700 \%$. This exceeds normal variation which makes it relevant to discuss. For $\mathrm{C}$ and $\mathrm{T}$ high ICCs are reported in standardised conditions. ${ }^{63}$

CK helps with the synthesis of ATP in muscles and increases after a match as a result of muscle damage. ${ }^{64-66}$ All studies that investigated CK took blood samples after a match. Interestingly, 11 studies reported much higher

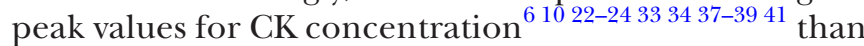
other included studies. ${ }^{192527283536}$ A possible explanation for this might be type of sport. High-peak values of CK were all found in soccer or rugby studies. The other studies represent more variation in type of sport. This suggests that soccer and rugby may be physically more demanding and muscle damage caused by, for example, distance covered, accelerations and high impacts is higher. ${ }^{38}$ 67-69 According to the literature this cannot be concluded unambiguously. ${ }^{70}$ However, taking competition level, position on the field ${ }^{21} 7172$ and type of methodology (eg, global positioning system, time-motion analyses) ${ }^{73} 74$ into account, it complements studies investigating player load or recovery in these sports. $4117075-79$

Three studies in soccer and rugby reported lower peak values. $^{272835}$ Deviation in one of these studies ${ }^{27}$ might be explained by the fact that samples were taken after a simulated match, while in all studies that reported highpeak values, samples were taken after an official match. 
Possibly, next to lower physical exertion during simulated matches,${ }^{80}$ lower peak values of CK can be expected.

$\mathrm{C}$ is an important catabolic stress response hormone and is considered to be increased as a result of playing a match. ${ }^{6481}$ The results of the included studies showed a high variance in time needed for $\mathrm{C}$ concentrations to decrease to baseline values. However, most soccer or rugby studies needed at least 48 hours to recover. ${ }^{10} 293738$ So, it seems that in line with $\mathrm{CK}$, also $\mathrm{C}$ is responsive to higher loads in soccer and rugby and this causes longer recovery times. This is in accordance with previous studies reporting a greater $\mathrm{C}$ response in higher intensity and longer duration. 8283

$\mathrm{T}$ is an anabolic hormone that stimulates glycogen synthesis and protein signalling which is needed for tissue repair. ${ }^{64} 8485$ In general, an unclear pattern of $\mathrm{T}$ responses is demonstrated by the included studies. This is in line with previous reported differences between rugby and other sports by Cormack $e t a t^{20}$ that support the high demands of this sport. In our systematic review one soccer and one rugby study reported higher $\mathrm{T}$ levels directly postmatch and returned to baseline within 18-24hours. ${ }^{35} 38$ Another two studies showed a decrease immediately postmatch followed by an increase to baseline within 14 hours $^{33}$ or delayed higher $\mathrm{T}$ levels in the following days ${ }^{42}$ in rugby players. Three studies showed a prolonged decrease that was interpreted as unclear and trivial by the authors, ${ }^{20}$ an increase to baseline after 60 hours ${ }^{29}$ or deviation still 48 hours postmatch. ${ }^{26}$ Finally, in four studies no significant change in $\mathrm{T}$ concentration was found. ${ }^{10} 192336$ Individual variability in $\mathrm{T}$ responses might explain the differences found in the studies.

\section{Practical perspective}

Overall, results of this systematic review suggest that team ball sports players need, in most cases, at least 48 hours to perform at the same level as prematch. Some biochemical markers needed to return to baseline values even longer. Especially, CK is increased for $\geq 72$ hours postmatch. This is the case for all team ball sports. However, CK reached higher values in soccer and rugby. In addition, for soccer and rugby it took longer to return to baseline for sprint performance, CK and $\mathrm{C}$ in comparison to other team ball sports.

The slow decrease in CK suggests that, although performance is already at prematch values, the muscles need more time to recover. This is an important finding that should be kept in mind working as a practitioner or support staff in daily practice with team ball sport players. In the decisions-making process of determining adequate recovery, coaches should distinguish short term and long term under recovery and consider context such as stage of season. If, for example, performance is unaffected during a tournament, but biochemical indicators are, one can still decide to play in optimal formation. This is especially true when full recovery is possible after the tournament and cumulative fatigue is avoided. However, if biochemical markers indicate poor recovery without upcoming phases of rest, then coaches could implement recovery strategies or prescribe rest within the training schedule. This seems important to avoid the ongoing process of insufficient recovery that is not directly demonstrated by performance tests. Based on practical perspective and cost-benefit arguments, one could decide to only perform biochemical analyses with clear indication of ongoing insufficient recovery during, for example, fixture congestion. Commonly used performance tests with their recovery time courses will then, in all likelihood, deviate from biochemical markers that could indicate more precise muscle damage.

Finally, there is a need to understand individual players and their recovery profiles. Recovery is highly dependent on both variation in load that players are exposed to during matches (eg, position dependent and variation of time during matches) and individual capacities (eg, aerobic and anaerobic). ${ }^{24} 32$ These capacities determine how players respond to the match load and play an important role in their ability to recover from that load. Therefore, it is crucial to monitor individual match load and recovery.

\section{Strengths and limitations}

This systematic review provides extensive insight in postmatch physical recovery in team ball sports with at least two postmatch measurements compared with prematch values. This satisfies the lack of a valuable overview of postmatch recovery time courses. Despite studies that not reported data in numbers in tables and/or text were excluded, results of these studies are affirmative with the results found. ${ }^{53} 57587986-88$

A limitation of this review is that it does not provide information on the available tests and processes of psychological recovery. It has been stated that a disturbed balance between both, physiological and psychological, stress and recovery can lead to maladaptation, and performance can be directly influenced by a poor mental state. ${ }^{89}$ However, the aim of this systematic review was to understand and compare objective, single-construct, recovery measures after matches.

\section{Future research}

Twenty-three out of 28 included studies investigated recovery in soccer or rugby. Unfortunately, studies in other sports were not as extensive as the soccer or rugby studies. Therefore, it is more difficult to get an indication of recovery of players from these sports. High-level original research is needed to get more insights in postmatch recovery in these sports. Furthermore, studies using recovery strategies or interventions were excluded from this review. Future studies should also evaluate the effects of these recovery strategies (eg, active recovery, sleep, mental recovery) on an individual level in the practical setting of team ball sports. 


\section{CONCLUSIONS}

This systematic review has demonstrated high variability in postmatch recovery time courses for various team ball sports within and between physical performance tests and biochemical markers. In addition, it is determined that CMJ height and sprint time recover faster than CK. For the short term, this suggests that on the basis of performance recovery players might be physically ready from 48 hours postmatch for a subsequent training or match. However, in the long run, demonstrated by the longer time course of recovery of CK ( $\geq 72$ hours), there might be the risk of ongoing insufficient recovery. For practitioners and support staff, it is important to have clear and complete insight in these recovery processes for different types of sports. Imposing load without sufficient recovery might lead to injuries, illnesses and non-functional over-reaching. ${ }^{91-93}$ Therefore, especially during fixture congestion with less than 48 hours of rest between consecutive matches, it is crucial to monitor match load and subsequent recovery closely based on recovery profiles. ${ }^{94}$

Contributors All authors contributed to the manuscript according to the four criteria of The International Committee of Medical Journal Editors Recommendations for the Conduct, Reporting, Editing, and Publication of Scholarly Work in Medical Journals (ICMJE Recommendations 2013): substantial contributions to the conception or design of the work; or the acquisition, analysis, or interpretation of data for the work; drafting the work or revising it critically for important intellectual content; final approval of the version to be published; and agreement to be accountable for all aspects of the work in ensuring that questions related to the accuracy or integrity of any part of the work are appropriately investigated and resolved.

Competing interests None declared.

Provenance and peer review Not commissioned; externally peer reviewed.

Open Access This is an Open Access article distributed in accordance with the Creative Commons Attribution Non Commercial (CC BY-NC 4.0) license, which permits others to distribute, remix, adapt, build upon this work non-commercially, and license their derivative works on different terms, provided the original work is properly cited and the use is non-commercial. See: http://creativecommons.org/ licenses/by-nc/4.0/

(C) Article author(s) (or their employer(s) unless otherwise stated in the text of the article) 2018. All rights reserved. No commercial use is permitted unless otherwise expressly granted.

\section{REFERENCES}

1. Strudwick AJ. Contemporary issues in the physical preparation of elite players. In:Williams A, ed. Science and soccer: developing elite performers. London: Routledge, 2012:335-56.

2. Andrzejewski M, Chmura J, Pluta B, et al. Analysis of sprinting activities of professional soccer players. J Strength Cond Res 2013;27:2134-40.

3. White AD, MacFarlane NG. Analysis of international competition and training in men's field hockey by global positioning system and inertial sensor technology. J Strength Cond Res 2015;29:137-43.

4. Póvoas SC, Seabra AF, Ascensão AA, et al. Physical and physiological demands of elite team handball. J Strength Cond Res 2012;26:3365-75.

5. Bishop PA, Jones E, Woods AK. Recovery from training: a brief review. J Strength Cond Res 2008;22:1015-24.

6. Russell M, Sparkes W, Northeast J, et al. Relationships between match activities and peak power output and creatine kinase responses to professional reserve team soccer match-play. Hum Mov Sci 2016;45:96-101.

7. Andersson $\mathrm{H}$, Karlsen A, Blomhoff R, et al. Active recovery training does not affect the antioxidant response to soccer games in elite female players. Br J Nutr 2010;104:1492-9.
8. Morton $\mathrm{RH}$. Modeling training and overtraining. J Sports Sci 1997;15:335-40.

9. Nédélec M, McCall A, Carling C, et al. Recovery in soccer: part I - post-match fatigue and time course of recovery. Sports Med 2012;42:997-1015.

10. Silva JR, Ascensão A, Marques F, et al. Neuromuscular function, hormonal and redox status and muscle damage of professional soccer players after a high-level competitive match. Eur J Appl Physiol 2013;113:2193-201.

11. Coughlan GF, Green BS, Pook PT, et al. Physical game demands in elite rugby union: a global positioning system analysis and possible implications for rehabilitation. J Orthop Sports Phys Ther 2011;41:600-5

12. Ziv G, Lidor R. Physical attributes, physiological characteristics, on-court performances and nutritional strategies of female and male basketball players. Sports Med 2009;39:547-68.

13. Saw AE, Main LC, Gastin PB. Monitoring the athlete training response: subjective self-reported measures trump commonly used objective measures: a systematic review. Br J Sports Med 2016:50:281-91.

14. Rowell AE, Aughey RJ, Hopkins WG, et al. Identification of sensitive measures of recovery after external load from football match play. Int J Sports Physiol Perform 2017;12:969-76.

15. Johnston MJ, Cook CJ, Drake D, et al. The neuromuscular, biochemical, and endocrine responses to a single-session vs. double-session training day in elite athletes. J Strength Cond Res 2016;30:3098-106.

16. Moher D, Liberati A, Tetzlaff J, et al. Preferred reporting items for systematic reviews and meta-analyses: the PRISMA statement. Ann Intern Med 2009;151:264-9.

17. Hopkins WG. A scale of magnitudes for effect statistics. In: a new view of statistics. $2011 \mathrm{http} / / /$ sportsci.org/resource/stats/index.html (accessed 15 Mar 2017).

18. Law M, Stewart D, Pollock N, et al. Critical review form-quantitative studies. McMaster University: Occupational Therapy EvidenceBased Practice Research Group, 1998.

19. Chatzinikolaou A, Christoforidis C, Avloniti A, et al. A microcycle of inflammation following a team handball game. J Strength Cond Res 2014:28:1981-94.

20. Cormack SJ, Newton RU, McGuigan MR. Neuromuscular and endocrine responses of elite players to an Australian rules football match. Int J Sports Physiol Perform 2008;3:359-74.

21. Duffield R, Murphy A, Snape A, et al. Post-match changes in neuromuscular function and the relationship to match demands in amateur rugby league matches. J Sci Med Sport 2012;15:238-43.

22. Fatouros IG, Chatzinikolaou A, Douroudos II, et al. Time-course of changes in oxidative stress and antioxidant status responses following a soccer game. J Strength Cond Res 2010;24:3278-86.

23. Ispirlidis I, Fatouros IG, Jamurtas AZ, et al. Time-course of changes in inflammatory and performance responses following a soccer game. Clin J Sport Med 2008;18:423-31.

24. Nedelec M, McCall A, Carling $C$, et al. The influence of soccer playing actions on the recovery kinetics after a soccer match. $J$ Strength Cond Res 2014;28:1517-23.

25. Pliauga $\mathrm{V}$, Kamandulis $\mathrm{S}$, Dargevičiūte $\mathrm{G}$, et al. The effect of a simulated basketball game on players' sprint and jump performance, temperature and muscle damage. J Hum Kinet 2015;46:167-75.

26. Romagnoli M, Sanchis-Gomar F, Alis R, et al. Changes in muscle damage, inflammation, and fatigue-related parameters in young elite soccer players after a match. J Sports Med Phys Fitness 2016;56:1198-205.

27. Twist C, Sykes D. Evidence of exercise-induced muscle damage following a simulated rugby league match. Eur J Sport Sci 2011;11:401-9.

28. Twist $\mathrm{C}$, Waldron $\mathrm{M}$, Highton J, et al. Neuromuscular, biochemical and perceptual post-match fatigue in professional rugby league forwards and backs. J Sports Sci 2012;30:359-67.

29. West DJ, Finn CV, Cunningham DJ, et al. Neuromuscular function, hormonal, and mood responses to a professional rugby union match. J Strength Cond Res 2014;28:194-200.

30. Hoffman JR, Nusse V, Kang J. The effect of an intercollegiate soccer game on maximal power performance. Can J Appl Physiol 2003;28:807-17.

31. McLellan CP, Lovell DI. Neuromuscular responses to impact and collision during elite rugby league match play. J Strength Cond Res 2012;26:1431-40.

32. Rampinini E, Bosio A, Ferraresi I, et al. Match-related fatigue in soccer players. Med Sci Sports Exerc 2011;43:2161-70.

33. Cunniffe B, Hore AJ, Whitcombe DM, et al. Time course of changes in immuneoendocrine markers following an international rugby game. Eur J Appl Physiol 2010;108:113-22. 
34. Djaoui L, Diaz-Cidoncha Garcia J, Hautier C, et al. Kinetic postmatch fatigue in professional and youth soccer players during the competitive period. Asian J Sports Med 2016;7:e28267.

35. Gravina L, Ruiz F, Lekue JA, et al. Metabolic impact of a soccer match on female players. J Sports Sci 2011;29:1345-52.

36. Kraemer WJ, Spiering BA, Volek JS, et al. Recovery from a national collegiate athletic association division I football game: muscle damage and hormonal status. J Strength Cond Res 2009;23:2-10.

37. McLellan CP, Lovell DI, Gass GC. Biochemical and endocrine responses to impact and collision during elite Rugby League match play. J Strength Cond Res 2011;25:1553-62.

38. McLellan CP, Lovell DI, Gass GC. Creatine kinase and endocrine responses of elite players pre, during, and post rugby league match play. J Strength Cond Res 2010;24:2908-19.

39. Russell M, Northeast J, Atkinson G, et al. Between-match variability of peak power output and creatine kinase responses to soccer match-play. J Strength Cond Res 2015;29:2079-85.

40. Souglis AG, Papapanagiotou A, Bogdanis GC, et al. Comparison of inflammatory responses to a soccer match between elite male and female players. J Strength Cond Res 2015;29:1227-33.

41. Takarada Y. Evaluation of muscle damage after a rugby match with special reference to tackle plays. Br J Sports Med 2003;37:416-9.

42. Elloumi M, Maso F, Michaux O, et al. Behaviour of saliva cortisol $[\mathrm{C}]$, testosterone $[\mathrm{T}]$ and the $\mathrm{T} / \mathrm{C}$ ratio during a rugby match and during the post-competition recovery days. Eur J Appl Physiol 2003;90:23-8.

43. Coad S, Gray B, Wehbe G, et al. Physical demands and salivary immunoglobulin A responses of elite Australian rules football athletes to match play. Int J Sports Physiol Perform 2015;10:613-7.

44. Currell K, Jeukendrup AE. Validity, reliability and sensitivity of measures of sporting performance. Sports Med 2008;38:297-316.

45. Cormack SJ, Newton RU, McGuigan MR, et al. Reliability of measures obtained during single and repeated countermovement jumps. Int J Sports Physiol Perform 2008;3:131-44.

46. Rodríguez-Rosell D, Mora-Custodio R, Franco-Márquez F, et al. Traditional vs. sport-specific vertical jump tests: reliability, validity, and relationship with the legs strength and sprint performance in adult and teen soccer and basketball players. J Strength Cond Res 2017;31:196-206.

47. Meylan C, McMaster T, Cronin J, et al. Single-leg lateral, horizontal, and vertical jump assessment: reliability, interrelationships, and ability to predict sprint and change-of-direction performance. $J$ Strength Cond Res 2009;23:1140-7.

48. Moir G, Shastri P, Connaboy C. Intersession reliability of vertical jump height in women and men. $J$ Strength Cond Res 2008:22:1779-84

49. Slinde F, Suber C, Suber L, et al. Test-retest reliability of three different countermovement jumping tests. $J$ Strength Cond Res 2008;22:640-4.

50. Wragg CB, Maxwell NS, Doust JH. Evaluation of the reliability and validity of a soccer-specific field test of repeated sprint ability. Eur $J$ Appl Physiol 2000;83:77-83.

51. Di Mascio M, Ade J, Bradley PS. The reliability, validity and sensitivity of a novel soccer-specific reactive repeated-sprint test (RRST). Eur J Appl Physiol 2015;115:2531-42.

52. Harper LD, Hunter R, Parker P, et al. Test-retest reliability of physiological and performance responses to 120 minutes of simulated soccer match play. $J$ Strength Cond Res 2016;30:3178-86.

53. Chatzinikolaou A, Draganidis D, Avloniti A, et al. The microcycle of inflammation and performance changes after a basketball match. J Sports Sci 2014;32:870-82.

54. Scanlan AT, Fox JL, Borges NR, et al. The commonality between approaches to determine jump fatigue during basketball activity in junior players: in-game versus across-game decrements. Int $J$ Sports Physiol Perform 2017;12:260-3.

55. Ben Abdelkrim N, El Fazaa S, El Ati J. Time-motion analysis and physiological data of elite under-19-year-old basketball players during competition. Br J Sports Med 2007;41:69-75.

56. Impellizzeri FM, Rampinini E, Marcora SM. Physiological assessment of aerobic training in soccer. J Sports Sci 2005;23:583-92.

57. Magalhães J, Rebelo A, Oliveira E, et al. Impact of Loughborough Intermittent Shuttle Test versus soccer match on physiological, biochemical and neuromuscular parameters. Eur J Appl Physiol 2010;108:39-48.

58. Ascensão A, Rebelo A, Oliveira E, et al. Biochemical impact of a soccer match - analysis of oxidative stress and muscle damage markers throughout recovery. Clin Biochem 2008;41:841-51.

59. Roe G, Darrall-Jones J, Till K, et al. Between-days reliability and sensitivity of common fatigue measures in rugby players. Int $J$ Sports Physiol Perform 2016;11:581-6.
60. Hartmann U, Mester J. Training and overtraining markers in selected sport events. Med Sci Sports Exerc 2000;32:209-15.

61. Heled Y, Bloom MS, Wu TJ, et al. CK-MM and ACE genotypes and physiological prediction of the creatine kinase response to exercise. J Appl Physiol 2007;103:504-10.

62. Mougios V. Reference intervals for serum creatine kinase in athletes. Br J Sports Med 2007;41:674-8.

63. Hackney AC, Zack E. Physiological day-to-day variability of select hormones at rest in exercise-trained men. $J$ Endocrinol Invest 2006;29:RC9-RC12.

64. Powers SK, Howley ET. Exercise physiology: theory and application to fitness and performance. New York: McGraw-Hill, 2012.

65. Johnston RD, Gabbett TJ, Jenkins DG. Influence of an intensified competition on fatigue and match performance in junior rugby league players. J Sci Med Sport 2013;16:460-5.

66. de Hoyo M, Cohen DD, Sañudo B, et al. Influence of football match time-motion parameters on recovery time course of muscle damage and jump ability. J Sports Sci 2016;34:1363-70.

67. Hoffman JR, Maresh CM, Newton RU, et al. Performance, biochemical, and endocrine changes during a competitive football game. Med Sci Sports Exerc 2002;34:1845-53.

68. Smart DJ, Gill ND, Beaven CM, et al. The relationship between changes in interstitial creatine kinase and game-related impacts in rugby union. Br J Sports Med 2008;42:198-201.

69. Jones MR, West DJ, Harrington BJ, et al. Match play performance characteristics that predict post-match creatine kinase responses in professional rugby union players. BMC Sports Sci Med Rehabil 2014;6:38.

70. Puente C, Abián-Vicén J, Areces F, et al. Physical and physiological demands of experienced male basketball players during a competitive game. J Strength Cond Res 2017;31:956-62.

71. McLellan CP, Lovell DI, Gass GC. Performance analysis of elite Rugby League match play using global positioning systems. $J$ Strength Cond Res 2011;25:1703-10.

72. Sirotic AC, Coutts AJ, Knowles $\mathrm{H}$, et al. A comparison of match demands between elite and semi-elite rugby league competition. J Sports Sci 2009;27:203-11.

73. Coutts AJ, Duffield R. Validity and reliability of GPS devices for measuring movement demands of team sports. J Sci Med Sport 2010;13:133-5.

74. Edgecomb SJ, Norton KI. Comparison of global positioning and computer-based tracking systems for measuring player movement distance during Australian football. J Sci Med Sport 2006;9:25-32.

75. Andrzejewski M, Chmura J, Pluta B, et al. Analysis of motor activities of professional soccer players. $J$ Strength Cond Res 2012;26:1481-8.

76. Wehbe GM, Hartwig TB, Duncan CS. Movement analysis of Australian national league soccer players using global positioning system technology. J Strength Cond Res 2014;28:834-42.

77. Gabbett T, King T, Jenkins D. Applied physiology of rugby league. Sports Med 2008;38:119-38.

78. King T, Jenkins D, Gabbett T. A time-motion analysis of professional rugby league match-play. J Sports Sci 2009;27:213-9.

79. Souglis A, Bogdanis GC, Giannopoulou I, et al. Comparison of inflammatory responses and muscle damage indices following a soccer, basketball, volleyball and handball game at an elite competitive level. Res Sports Med 2015;23:59-72.

80. Murphy AP, Duffield R, Kellett A, et al. A Comparison of the perceptual and technical demands of tennis training, simulated match play, and competitive tournaments. Int J Sports Physiol Perform 2016;11:40-7.

81. Urhausen A, Gabriel H, Kindermann W. Blood hormones as markers of training stress and overtraining. Sports Med 1995;20:251-76.

82. Port K. Serum and saliva cortisol responses and blood lactate accumulation during incremental exercise testing. Int J Sports Med 1991;12:490-4.

83. Lac G, Berthon P. Changes in cortisol and testosterone levels and $\mathrm{T} / \mathrm{C}$ ratio during an endurance competition and recovery. $J$ Sports Med Phys Fitness 2000;40:139-44.

84. Salvadora A, Suay F, Martinez-Sanchis S, et al. Correlating testosterone and fighting in male participants in judo contests. Physiol Behav 1999;68:205-9.

85. Spiering BA, Kraemer WJ, Anderson JM, et al. Resistance exercise biology: manipulation of resistance exercise programme variables determines the responses of cellular and molecular signalling pathways. Sports Med 2008;38:527-40.

86. Draganidis D, Chatzinikolaou A, Avloniti A, et al. Correction: recovery kinetics of knee flexor and extensor strength after a football match. PLoS One 2015;10:e0133459. 
87. Marin DP, dos Santos RC, Bolin AP, et al. Cytokines and oxidative stress status following a handball game in elite male players. Oxid Med Cell Longev 2011;2011:1-10.

88. Sterczala AJ, Flanagan SD, Looney DP, et al. Similar hormonal stress and tissue damage in response to national collegiate athletic association division i football games played in two consecutive seasons. J Strength Cond Res 2014;28:3234-8.

89. Kenttä G, Hassmén P. Overtraining and recovery. A conceptual model. Sports Med 1998;26:1-16.

90. Beedie CJ, Terry PC, Lane AM. The profile of mood states and athletic performance: Two meta-analyses. J Appl Sport Psychol 2000;12:49-68.
91. Budgett R. Fatigue and underperformance in athletes: the overtraining syndrome. Br J Sports Med 1998;32:107-10.

92. Brink MS, Visscher C, Arends S, et al. Monitoring stress and recovery: new insights for the prevention of injuries and illnesses in elite youth soccer players. Br J Sports Med 2010;44:809-15.

93. Schmikli SL, Brink MS, de Vries WR, et al. Can we detect nonfunctional overreaching in young elite soccer players and middlelong distance runners using field performance tests? Br J Sports Med 2011;45:631-6.

94. Doeven SH, Brink MS, Frencken WG, et al. Impaired player-coach perceptions of exertion and recovery during match congestion. Int $J$ Sports Physiol Perform 2017;17:1-20. 